\title{
Presentation and management of lateral sinus thrombosis following posterior fossa surgery
}

\author{
Caroline Apra, MSc, ${ }^{1,2}$ Owais Kotbi, MD, ${ }^{2,3}$ Guillaume Turc, MD, PhD, ${ }^{2,4,5}$ Robert Corns, MD, ${ }^{6}$ \\ Mélanie Pagès, MD,, Raphaëlle Souillard-Scémama, MD, ,,3 Edouard Dezamis, MD,, ${ }^{1,2}$ \\ Eduardo Parraga, MD, , Jean-François Meder, MD, PhD, ${ }^{2,3,5}$ Xavier Sauvageon, MD, ${ }^{2,8}$ \\ Bertrand Devaux, MD, ${ }^{1,2}$ Catherine Oppenheim, MD, PhD, ${ }^{2,3,5}$ and Johan Pallud, MD, PhD ${ }^{1,2}$
}

\begin{abstract}
Departments of ${ }^{1}$ Neurosurgery, ${ }^{3}$ Neuroradiology, ${ }^{4}$ Neurology, ${ }^{7}$ Neuropathology, and ${ }^{8}$ Neuro-Anaesthesia and Neuro-Intensive Care, Sainte-Anne Hospital; ${ }^{2}$ Paris Descartes University, Sorbonne Paris Cité; ${ }^{5}$ INSERM U894, Paris, France; and ${ }^{6}$ Department of Neurosurgery, Leeds General Infirmary, Leeds, United Kingdom
\end{abstract}

\begin{abstract}
OBJECTIVE There are no guidelines for the management of postoperative lateral sinus thrombosis following posterior fossa surgery. Introducing treatment-dose anticoagulant therapy during the immediate postoperative period increases the risk of intracranial bleeding. This study assessed the incidence of and risk factors associated with postoperative lateral sinus thrombosis and the complications related to thrombosis and/or anticoagulation.
\end{abstract}

METHODS This study was a retrospective monocentric analysis of adult patients who underwent surgical removal of a posterior fossa space-occupying lesion with available postoperative imaging. Postoperative lateral sinus thrombosis was defined as a T2* hypointensity within the venous sinus and/or a filling defect on postcontrast MRI or CT scan.

RESULTS Among 180 patients, $12(6.7 \% ; 95 \% \mathrm{Cl} 3.0-10.4)$ were found to have lateral sinus thrombosis on postoperative imaging, none of whom were symptomatic. Unadjusted risk factors for postoperative lateral sinus thrombosis were a history of deep venous thrombosis $(p=0.016)$, oral contraceptive pill $(p=0.004)$, midline surgical approach $(p=0.035)$, and surgical exposure of the sinus $(p<0.001)$. Seven of the patients $(58.3 \%)$ with a postoperative lateral sinus thrombosis received immediate treatment-dose anticoagulant therapy. Lateral sinus recanalization occurred radiologically at a mean time of $272 \pm 23$ days in $85.7 \%$ of patients (6 of 7 ) undergoing treatment-dose anticoagulant therapy and in $20 \%$ of patients (1 of 5) not receiving treatment-dose anticoagulant therapy. Postoperative complications occurred in $56.2 \%$ of patients (9 of 16) who received treatment-dose curative anticoagulant therapy and in $27 \%$ of patients (45 of 164) who did not.

CONCLUSIONS Incidental radiological lateral sinus thrombosis following posterior fossa surgery has an incidence of $6.7 \%$. To further define the benefit-to-risk ratio of a treatment-dose anticoagulant therapy, a prospective trial should be considered.

http://thejns.org/doi/abs/10.3171/2015.11.JNS151881

KEY WORDS anticoagulation; lateral sinus; posterior fossa; surgery; thrombosis; vascular disorders

$\mathrm{P}$ ATIENTS who undergo neurosurgical procedures are at risk for perioperative deep venous thrombosis, especially in the case of intracranial surgery. The overall incidence of deep venous thrombosis and pulmonary embolism has been reported to be between $6 \%$ and $50 \%$ in patients undergoing a craniotomy. ${ }^{1,7}$ Therefore, prophylactic anticoagulation during the postoperative period is recommended, although it is estimated to increase the risk of intracranial hemorrhage from $1 \%$ to $11 \% .^{1,14}$ Neurosurgical patients are also at risk for postoperative cerebral venous thrombosis, mainly of the lateral sinus in the case of posterior fossa surgery. It has been reported that following surgery for cerebellopontine angle tumors, the incidence of postoperative lateral sinus thrombosis is $11.6 \%$ (95\% CI 2.0-20.2). ${ }^{13}$ There is a broad range of clinical presentations, from asymptomatic to potentially severe, such as hydrocephalus, epilepsy, and death. ${ }^{12}$ There are no other studies regarding posterior fossa for other lesions. Therefore, the incidence, clinical presentation, and prognosis of postoperative lateral sinus thrombosis are largely unknown. In the absence of practical guidelines and to inform decision making, we assessed the following: 1) the 
incidence of postoperative lateral sinus thrombosis following surgery for any posterior fossa lesion in adults; 2) the risk factors associated with this condition; and 3) the thrombosis- and anticoagulation-related complications.

\section{Methods \\ Data Source and Study Design}

We retrospectively analyzed all patients who underwent surgical treatment at a single institution for a posterior fossa space-occupying lesion between January 2008 and May 2014. Inclusion criteria were: 1) patients $\geq 18$ years old; 2) posterior fossa craniectomy (midline, paramedian, or lateral suboccipital approach) for the removal of a space-occupying lesion; 3) available preoperative imaging (MRI and/or postcontrast CT scan); 4) available digitized postoperative follow-up imaging (MRI and/or postcontrast CT scan); and 5) at least 6 months of postoperative clinical and imaging follow-up.

\section{Diagnosis of Postoperative Lateral Sinus Thrombosis}

One reader (C.A.), who was blinded to clinical data, reviewed all preoperative images to ensure that no lateral sinus thrombosis was patent before surgery. Two readers (C.A. and O.K.), who were blinded to clinical data, independently reviewed postoperative images to search for lateral sinus thrombosis. A senior neuroradiologist (C.O.) adjudicated all cases of postoperative lateral sinus thrombosis and resolved discordances. Lateral sinus thrombosis was defined as a T2* hypointensity within the venous sinus and/or by a flow defect on a postoperative contrastenhanced 3D T1-weighted sequence or postcontrast CT scan. In case of a postoperative lateral sinus thrombosis, all available subsequent follow-up images were analyzed to document whether and when the thrombus disappeared.

\section{Data Collection}

The following variables were collected from the medical records, using a standardized form: sex, age, history of neoplasm, deep venous thrombosis, smoking, medications (e.g., oral contraceptives, anticoagulant therapy, or antiplatelet drugs), Karnofsky Performance Scale score, location of lesion, lesion size, and histopathological diagnosis. Surgery-related details collected included the following: duration of surgery, extent of craniectomy, lateral sinus exposure, lateral sinus opening, dural coagulation toward lateral sinus, and duraplasty. Follow-up-related characteristics included the following: early and long-term postoperative complications (e.g., lateral sinus thrombosis, other deep venous thrombosis, pulmonary embolism, surgical bed hemorrhage, second-look surgery, hydrocephalus, scar defect, infection, or other complication), postoperative anticoagulation, postoperative imaging, and clinical follow-up.

\section{Statistical Analyses}

Continuous variables are described as the mean $\pm \mathrm{SD}$ (range). Categorical variables are described as percentages. We assessed risk factors for postoperative lateral sinus thrombosis in patients who underwent a posterior fossa craniectomy for resection of a space-occupying lesion and who had a postoperative lateral sinus thrombosis (thrombosis group) compared with those who did not (nonthrombosis group). Univariable analyses were performed, computing unadjusted odds ratios and using the chi-square or Fisher's exact test for comparing categorical variables, and the unpaired t-test or Mann-Whitney U-test for continuous variables, as appropriate. Multivariable analyses were not performed given the low number of events. A p value < 0.05 was considered significant. Statistical analyses were performed using JMP version 11.0.0 (SAS Institute) and SPSS Statistics version 20.0 (IBM Corp.) software.

\section{Results \\ Study Population}

A total of 201 patients were screened. We excluded 21 patients $(10.4 \%)$ who did not have the required postoperative imaging $(n=12)$ or imaging follow-up $(n=9)$, leaving 180 patients for the present analysis. The included patients (99 women and 81 men) had a mean age of $52 \pm 7$ years (range 18-81 years). Eighty-six patients (48\%) had metastases, 43 (24\%) had primary cerebral neoplasms, 27 (15\%) had meningiomas, 16 (9\%) had acoustic schwannomas, and $8(4 \%)$ had nonneoplastic mass lesions. The patients' main characteristics are summarized in Table 1.

\section{Postoperative Lateral Sinus Thrombosis}

Twelve patients $(6.7 \%$; 95\% CI 3.0-10.4) had lateral sinus thrombosis on postoperative imaging (169 of $180 \mathrm{pa}-$ tients underwent MRI and 11 had postcontrast CT scans), which was performed at a mean of $2.5 \pm 0.2$ days (range 0-52 days) following surgery. Lateral sinus thromboses were ipsilateral to the operating site in all cases. They were limited to the sigmoid sinus in 4 cases, to the transverse sinus in 1 case, or extended to both transverse and sigmoid sinuses in the remaining 7 cases. An illustrative case is shown in Fig. 1. None of the thromboses were present on preoperative imaging (145 of 180 patients underwent MRI and 35 had postcontrast CT scans) performed at a mean of $15.1 \pm 1.5$ days (range 1-170 days) before surgery. Nine lateral sinus thromboses (75\%) were detected at the time of initial radiological reporting, whereas the other 3 cases were undiagnosed until the present retrospective analysis. Of the 12 patients harboring a lateral sinus thrombosis, none had any related neurological symptoms or signs during the early postoperative period and within 6 months of follow-up. The main characteristics of the patients with lateral sinus thrombosis are summarized in Table 2.

\section{Management of Postoperative Lateral Sinus Thrombosis}

Of the 9 patients who were contemporaneously diagnosed with postoperative lateral sinus thrombosis, 7 received immediate treatment-dose anticoagulant therapy with enoxaparin (8000 IU twice per day), and 1 patient was switched from enoxaparin to oral anticoagulation. Immediate treatment-dose anticoagulant therapy was decided on an individual basis in the absence of institutional guidelines: introduction in 7 cases (intraoperative lateral sinus damage in 2 cases, history of pulmonary embolism in 1 case, extensive lateral sinus thrombosis in 1 case, associated cerebellar ischemia in 1 case, and unknown reasons in 
TABLE 1. Main characteristics of 180 adult patients who underwent surgical removal of a posterior fossa space-occupying lesion*

\begin{tabular}{|c|c|c|c|c|c|c|}
\hline \multirow[b]{2}{*}{ Parameter } & \multicolumn{2}{|c|}{ Whole Series $(n=180)$} & \multicolumn{2}{|c|}{$\begin{array}{l}\text { Nonthromb Group } \\
\qquad(n=168)\end{array}$} & \multicolumn{2}{|c|}{$\begin{array}{l}\text { Lateral Sinus Thromb } \\
\text { Group }(n=12)\end{array}$} \\
\hline & No. & $\%$ & No. & $\%$ & No. & $\%$ \\
\hline \multicolumn{7}{|l|}{ Clinical } \\
\hline \multicolumn{7}{|l|}{ Sex } \\
\hline M & 81 & 45 & 78 & 46 & 3 & 25 \\
\hline $\mathrm{F}$ & 99 & 55 & 90 & 54 & 9 & 75 \\
\hline Age in yrs, mean \pm SD & \multicolumn{2}{|c|}{$52 \pm 7$} & \multicolumn{2}{|c|}{$52 \pm 7$} & \multicolumn{2}{|c|}{$51 \pm 8$} \\
\hline \multicolumn{7}{|l|}{ No. of surgeries } \\
\hline 1 & 165 & 92 & 154 & 92 & 11 & 92 \\
\hline 2 & 6 & 3.3 & 6 & 4 & 0 & 0 \\
\hline 3 & 1 & 0.6 & 0 & 0 & 1 & 8 \\
\hline \multicolumn{7}{|l|}{ Medical history } \\
\hline Deep venous thromb & 8 & 4 & 5 & 3 & 3 & 25 \\
\hline Hormonal contraception & 2 & 1 & 0 & 0 & 2 & 17 \\
\hline Smoking & 38 & 21 & 35 & 21 & 3 & 25 \\
\hline Neoplasm & 78 & 43 & 74 & 44 & 4 & 33 \\
\hline AC therapy & 13 & 7 & 12 & 7 & 1 & 8 \\
\hline Antiplatelets & 11 & 6 & 11 & 7 & 0 & 0 \\
\hline \multicolumn{7}{|l|}{ Imaging \& histopathological } \\
\hline \multicolumn{7}{|l|}{ Lesion location } \\
\hline Intradural & 139 & 77 & 131 & 78 & 8 & 67 \\
\hline Extradural & 41 & 23 & 37 & 22 & 4 & 33 \\
\hline Lesion in contact w/ lateral sinus & 23 & 13 & 22 & 13 & 1 & 8 \\
\hline Lesion in contact w/ midline & 70 & 39 & 68 & 40 & 2 & 17 \\
\hline Lesion diameter in $\mathrm{mm}$, mean $\pm \mathrm{SD}$ & \multicolumn{2}{|c|}{$35 \pm 6$} & \multicolumn{2}{|c|}{$35 \pm 6$} & \multicolumn{2}{|c|}{$36 \pm 8$} \\
\hline \multicolumn{7}{|l|}{ Histopathological Dx } \\
\hline Malignant & 98 & 54 & 93 & 55 & 5 & 42 \\
\hline Nonmalignant & 82 & 46 & 75 & 45 & 7 & 58 \\
\hline Metastases & 86 & 48 & 81 & 48 & 5 & 42 \\
\hline Primary cerebral tumors & 43 & 24 & 40 & 24 & 3 & 25 \\
\hline Meningiomas & 27 & 15 & 24 & 14 & 3 & 25 \\
\hline Schwannomas & 16 & 9 & 15 & 9 & 1 & 8 \\
\hline Abscess & 1 & $<1$ & 1 & $<1$ & 0 & 0 \\
\hline Cavernoma & 2 & 1 & 2 & 1 & 0 & 0 \\
\hline Epidermoid cysts & 5 & 3 & 5 & 3 & 0 & 0 \\
\hline \multicolumn{7}{|l|}{ Surgical \& therapeutic } \\
\hline Duration of op in mins, mean \pm SD & \multicolumn{2}{|c|}{$221 \pm 55$} & \multicolumn{2}{|c|}{$218 \pm 54$} & \multicolumn{2}{|c|}{$266 \pm 69$} \\
\hline$>120$ mins & 110 & 86 & 101 & 60 & 9 & 75 \\
\hline$\leq 120$ mins & 18 & 14 & 17 & 10 & 1 & 8 \\
\hline Lateral sinus exp & 45 & 25 & 36 & 21 & 9 & 75 \\
\hline Midline exp & 95 & 53 & 92 & 55 & 3 & 25 \\
\hline Dura mater extensive coagulation & 13 & 7 & 12 & 7 & 1 & 8 \\
\hline Lateral sinus injury & 8 & 4 & 6 & 4 & 2 & 17 \\
\hline Duraplasty & 53 & 29 & 51 & 30 & 2 & 17 \\
\hline \multicolumn{7}{|l|}{ Postop management } \\
\hline Postop complications & & & & & & \\
\hline Extracranial venous thromb & 6 & 3 & 5 & 3 & 1 & 8 \\
\hline
\end{tabular}


» CONTINUED FROM PAGE 10

TABLE 1. Main characteristics of 180 adult patients who underwent surgical removal of a posterior fossa space-occupying lesion*

\begin{tabular}{|c|c|c|c|c|c|c|}
\hline \multirow[b]{2}{*}{ Parameter } & \multicolumn{2}{|c|}{ Whole Series $(n=180)$} & \multicolumn{2}{|c|}{$\begin{array}{l}\text { Nonthromb Group } \\
\quad(n=168)\end{array}$} & \multicolumn{2}{|c|}{$\begin{array}{l}\text { Lateral Sinus Thromb } \\
\text { Group }(n=12)\end{array}$} \\
\hline & No. & $\%$ & No. & $\%$ & No. & $\%$ \\
\hline \multicolumn{7}{|l|}{ Postop management (continued) } \\
\hline \multicolumn{7}{|c|}{ Postop complications (continued) } \\
\hline Lateral sinus thromb & 12 & 7 & NA & NA & - & - \\
\hline Infection & 20 & 11 & 18 & 11 & 2 & 17 \\
\hline Hydrocephalus & 21 & 12 & 20 & 12 & 1 & 8 \\
\hline Intracerebral hemorrhage & 19 & 11 & 19 & 11 & 0 & 0 \\
\hline Scar opening or collection & 25 & 14 & 23 & 14 & 2 & 17 \\
\hline \multicolumn{7}{|l|}{ Postop management } \\
\hline Preventive AC & 144 & 80 & 135 & 80 & 9 & 75 \\
\hline Curative AC & 16 & 9 & 9 & 5 & 7 & 58 \\
\hline Need for a 2nd op & 27 & 15 & 26 & 15 & 2 & 17 \\
\hline
\end{tabular}

$\mathrm{AC}=$ anticoagulation; $\mathrm{Dx}=$ diagnosis; $\exp =$ exposure; $\mathrm{NA}=$ not applicable; thromb = thrombosis.

* Characteristics of the whole study population $(n=180)$, divided into nonthrombosis group $(n=168)$ and thrombosis group $(n=12)$, for clinical, imaging, histopathological, and surgical parameters. The thrombosis group includes all cases with a postoperative lateral sinus thrombosis.

the remaining 2 cases) and no introduction in 2 cases (late diagnosis in 1 case and small lateral sinus thrombosis in 1 case). Anticoagulant therapy was stopped when imaging follow-up showed sinus recanalization, or after 3 months when patients remained stable. The 5 untreated patients $(2$ detected and 3 undetected lateral sinus thromboses at the time of initial radiological reporting) received a standard prophylactic dose of anticoagulant therapy with low-dose enoxaparin (4000 IU per day) until discharge. Follow-up imaging demonstrated a lateral sinus recanalization in 7 patients (58.3\%) after $272 \pm 23$ days (range 6-1464 days) and a persisting lateral sinus thrombosis in 5 patients $(41.7 \%)$ on the most recent follow-up imaging at $1393 \pm 338$ days (range 839-2364 days). The treatment-dose anticoagulant therapy seemed to increase the rate of long-term lateral sinus recanalization $(85.7 \%$; 6 of 7 patients) compared with untreated patients $(20.0 \%$; 1 of 5 patients), without reaching statistical significance $(\mathrm{p}=0.189)$.

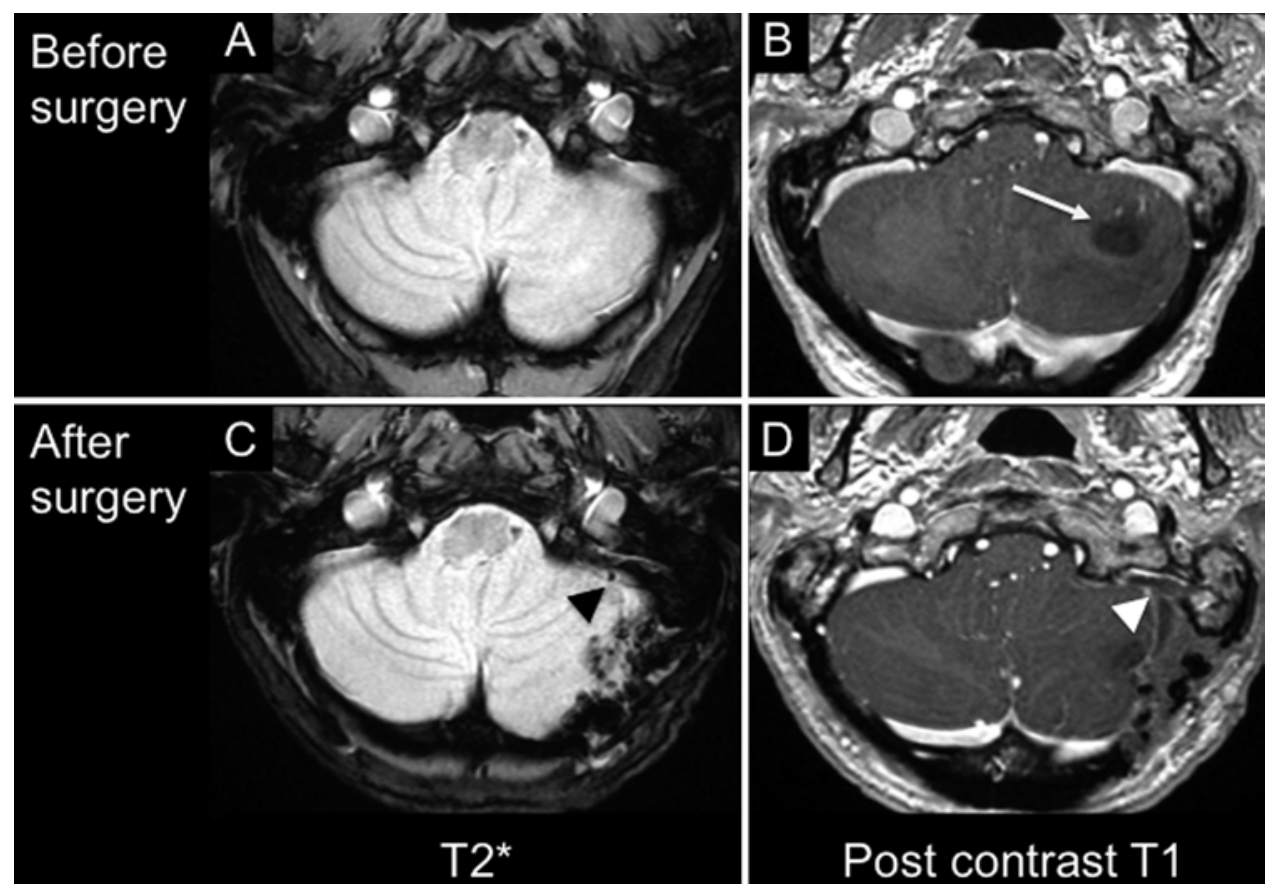

FIG. 1. Example of a thrombus of the left sigmoid sinus following the resection of a left cerebellar hemangioblastoma (A and $\mathbf{B})$ in a 63-year-old man who presented with headaches and a cerebellar syndrome. The sigmoid sinus thrombosis is demonstrated on 1-day postoperative MRI as a hypointense clot on $\mathrm{T} 2^{*}(\mathbf{C})$ and as a hypointense filling defect on the postcontrast T1-weighted sequence (D). The white arrow in panel B, black arrowhead in panel C, and white arrowhead in panel D point to the clot. 


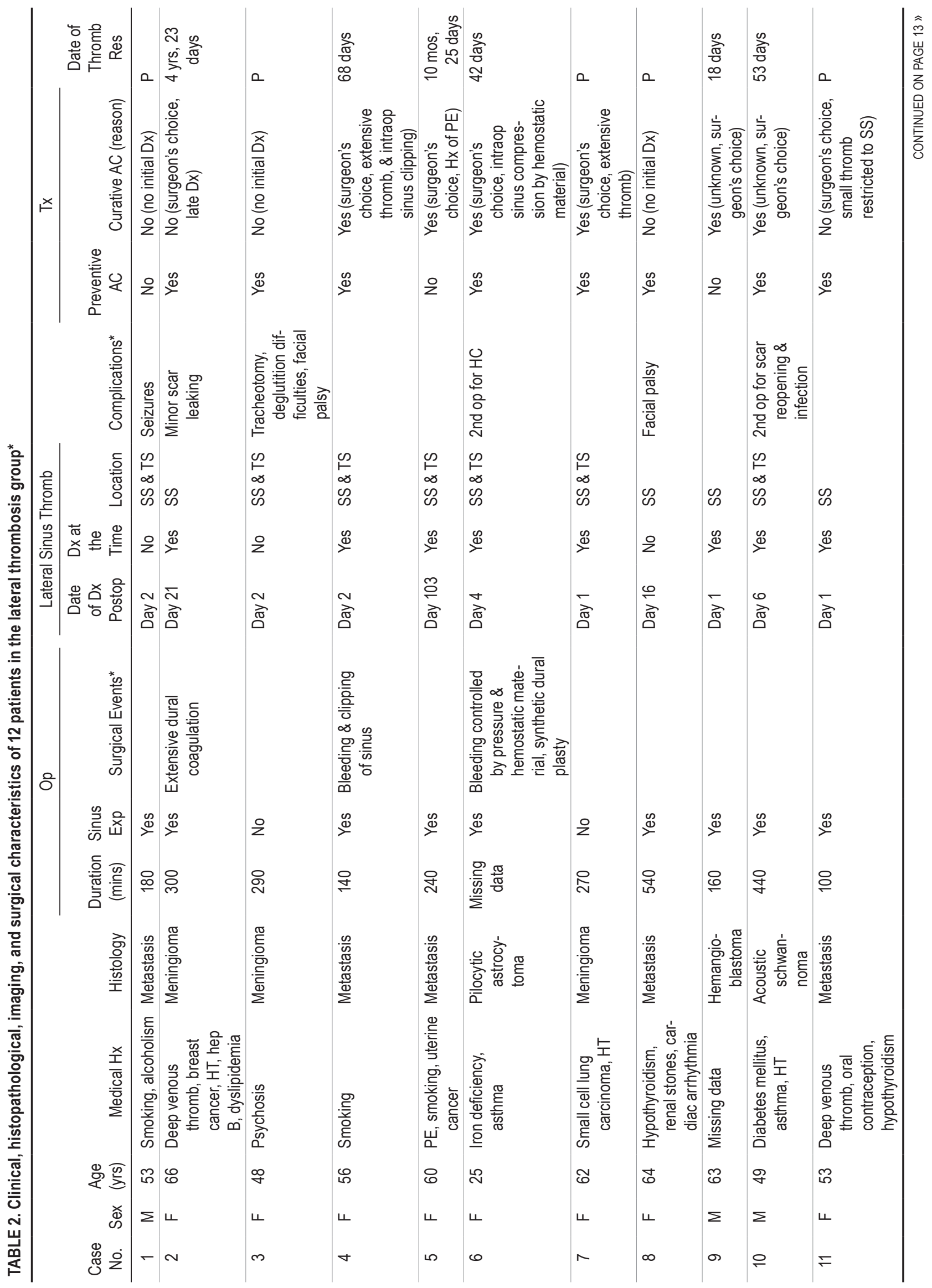




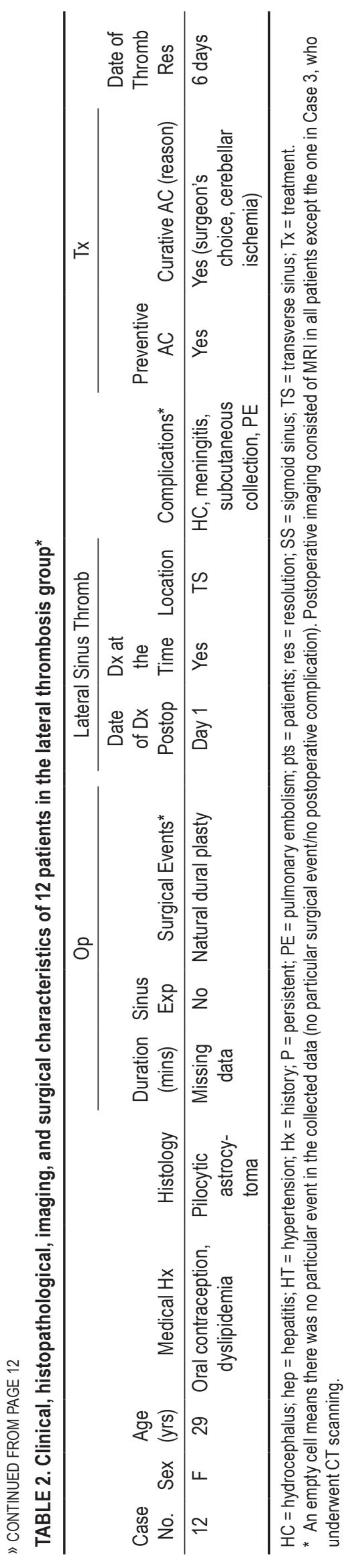

\section{Surgical Outcomes}

The incidence of surgical complications was $28.0 \%$ (47 of 168 patients) in the nonthrombosis group and $50.0 \%$ (6 of 12 patients) in the thrombosis group. A postoperative hydrocephalus requiring internal shunting was seen in $16.7 \%$ of patients ( 2 of 12 ) with lateral sinus thrombosis versus $11.3 \%$ of patients (19 of 168) without lateral sinus thrombosis. The incidence of surgical complications was significantly higher in patients who received treatmentdose anticoagulant therapy for postoperative lateral sinus thrombosis $(\mathrm{n}=7)$ or other postoperative thromboembolic events $(n=9)(56.2 \%$; 9 of 16 patients) than in patients who did not receive such therapy (27.0\%; 45 of 164 patients) (p $=0.020$ ). Indeed, a second-look surgery was performed in 6 of 16 patients (37.5\%) versus 22 of 164 patients (13.4\%); a surgical bed hemorrhage was observed in 3 of 16 patients (18.8\%) versus 17 of 164 patients (10.4\%); and a scar defect was observed in 3 of 16 patients (18.8\%) versus 14 of 164 patients $(8.5 \%)$. Of note, 1 patient with a postoperative lateral sinus thrombosis who received treatment-dose anticoagulant therapy had a scar defect secondary to a subcutaneous hematoma that required a surgical evacuation during the early postoperative period. No treatment-related complications were observed at 6 months of follow-up. Patients with untreated postoperative lateral sinus thrombosis did not develop neurological worsening, ischemic events, symptomatic pulmonary embolism, or deep venous thrombosis during the early postoperative period and at 6 months of follow-up.

\section{Risk Factors for Postoperative Lateral Sinus Thrombosis}

As shown in Table 3, risk factors associated with postoperative lateral sinus thrombosis in univariable analysis were oral contraceptive pill usage $(\mathrm{p}=0.004)$, medical history of venous thrombosis $(\mathrm{p}=0.016)$, midline surgical approach $(\mathrm{p}=0.035)$, and intraoperative lateral sinus exposure $(\mathrm{p}<0.001)$. None of the other surgical parameters, such as accidental opening of the lateral sinus $(\mathrm{p}=0.097)$, dura mater coagulation over the sinus $(\mathrm{p}=0.619)$, or duraplasty $(\mathrm{p}=0.412)$, were significantly associated with postoperative lateral sinus thrombosis.

\section{Discussion}

The incidence, clinical impact, risk factors, and evolution of radiological postoperative lateral sinus thrombosis following posterior fossa surgery of a space-occupying lesion have been largely unknown. We show for the first time, in a retrospective, single-institution series of 180 adult patients, that postoperative lateral sinus thromboses occur in approximately $7 \%$ of cases following a posterior fossa surgery, are not restricted to cerebellopontine angle tumor resection, and are well tolerated without long-term impairment. In addition, we identified history of deep venous thrombosis, oral contraceptive pill use, midline surgical approach, and surgical exposure of the lateral sinus as risk factors.

\section{Incidence of Postoperative Lateral Sinus Thrombosis}

No previous study has examined the incidence of radiological postoperative lateral sinus thrombosis following suboccipital craniectomy. Herein, we show that it is 
TABLE 3. Logistic regression model of risk factors for postoperative lateral sinus thrombosis in 180 adult patients*

\begin{tabular}{|c|c|c|c|c|}
\hline Parameters & No. & OR & $95 \% \mathrm{Cl}$ & $p$ Value \\
\hline \multicolumn{5}{|l|}{ Clinical } \\
\hline \multicolumn{5}{|l|}{ Sex } \\
\hline$M$ & 3 & 1 (ref) & - & - \\
\hline $\mathrm{F}$ & 9 & 2.67 & $0.76-12.31$ & 0.128 \\
\hline \multicolumn{5}{|l|}{ No. of ops } \\
\hline 1 & 165 & 1 (ref) & - & - \\
\hline$\geq 2$ & 15 & 0.99 & $0.12-8.27$ & 1.00 \\
\hline \multicolumn{5}{|l|}{ Age, yrs } \\
\hline$<50$ & 3 & 1 (ref) & - & - \\
\hline$\geq 50$ & 9 & 1.96 & $0.56-9.08$ & 0.304 \\
\hline \multicolumn{5}{|l|}{ Medical history } \\
\hline Deep venous thromb & 3 & 8.94 & $1.92-41.70$ & 0.016 \\
\hline Oral contraception & 2 & - & - & 0.004 \\
\hline Smoking & 3 & 1.21 & $0.31-4.72$ & 0.508 \\
\hline Neoplasm & 4 & 0.63 & $0.18-2.17$ & 0.335 \\
\hline AC therapy & 1 & 1.17 & $0.14-9.88$ & 0.607 \\
\hline Antiplatelets & 0 & - & - & 1.00 \\
\hline \multicolumn{5}{|l|}{ Imaging \& histopathological } \\
\hline \multicolumn{5}{|l|}{ Lesion location } \\
\hline Extradural & 4 & 1 (ref) & - & - \\
\hline Intradural & 8 & 0.57 & $0.16-2.00$ & 0.475 \\
\hline Lesion contacting lateral sinus & 1 & 0.59 & $0.07-4.81$ & 0.520 \\
\hline Lesion contacting midline & 4 & 0.75 & $0.22-2.59$ & 0.448 \\
\hline \multicolumn{5}{|l|}{ Mean lesion diameter, $\mathrm{mm}$} \\
\hline$<35$ & 3 & 1 (ref) & - & - \\
\hline$\geq 35$ & 6 & 1.79 & $0.43-7.45$ & 0.505 \\
\hline \multicolumn{5}{|l|}{ Histopathological Dx } \\
\hline Nonmalignant & 7 & 1 (ref) & - & - \\
\hline Malignant & 5 & 0.06 & $0.17-31.86$ & 0.260 \\
\hline \multicolumn{5}{|l|}{ Histopathological subtype } \\
\hline Other & 11 & 1 (ref) & - & - \\
\hline Schwannoma & 1 & 0.92 & $0.11-7.63$ & 1.00 \\
\hline \multicolumn{5}{|l|}{ Surgical \& therapeutic } \\
\hline \multicolumn{5}{|l|}{ Duration of op, mins } \\
\hline$\leq 120$ & 1 & 1 (ref) & - & - \\
\hline$>120$ & 9 & 1.51 & $0.18-12.73$ & 1.00 \\
\hline Lateral sinus exp & 9 & 10.50 & $2.70-40.83$ & $<0.001$ \\
\hline Midline exp & 3 & 0.26 & $0.07-0.98$ & 0.035 \\
\hline Dura mater extensive coagulation & 1 & 1.14 & $0.14-9.56$ & 0.619 \\
\hline Lateral sinus injury & 2 & 5.20 & $0.93-29.14$ & 0.097 \\
\hline Duraplasty & 2 & 0.54 & $0.09-3.36$ & 0.412 \\
\hline \multicolumn{5}{|l|}{ Postop management } \\
\hline Preventive AC & 9 & 0.71 & $0.18-2.78$ & 0.427 \\
\hline Extracranial deep venous thromb & 1 & 4.97 & $0.48-51.80$ & 0.467 \\
\hline Surgical bed infection & 2 & 1.66 & $0.34-8.16$ & 0.710 \\
\hline Scar opening, subcutaneous collection & 3 & 2.32 & $0.58-9.25$ & 0.495 \\
\hline Hydrocephalus & 2 & 1.56 & $0.32-7.65$ & 0.763 \\
\hline Surgical bed hemorrhage & 0 & - & - & \\
\hline Need for a 2nd op & 3 & 2.09 & $0.53-8.29$ & 0.510 \\
\hline
\end{tabular}

Ref $=$ reference (referral for statistical analyses); $-=$ no event.

* Unadjusted odds ratios for potential risk factors and complications compared in the nonthrombosis and thrombosis groups. 
not a rare event (incidence $6.7 \%$ [95\% CI 3.0-10.4]) in an observational retrospective series of 180 adult patients who underwent suboccipital craniectomy for a variety of conditions. This is in agreement with a previous study by Keiper et al., which reported 5 postoperative lateral sinus thromboses $(4.7 \%)$ following 107 suboccipital craniectomies or translabyrinthine craniectomies, without detailing the thrombosis rate by surgical approach. ${ }^{12}$ However, postoperative lateral sinus thrombosis appears to be less frequent following suboccipital craniectomy than following a cerebellopontine angle surgery; Moore et al. reported 5 postoperative lateral sinus thromboses $(11.6 \%)$ following 43 cerebellopontine angle surgeries. ${ }^{13}$ Here, the systematic analysis of preoperative MR images allowed us to conclude that the observed lateral sinus thromboses are consequences of the surgery. There is a differential diagnosis for the radiological appearance of sinus thrombosis, including endosinusal granulations, ${ }^{6}$ surgical material in the sinus, and extrinsic compression. To enhance the diagnostic accuracy, we checked that thrombosis was visible on several acquisition planes, and on several MR sequences. We also verified that the filling defect was not present on preoperative MRI, to formally exclude the possibility of large endosinus granulation. In addition, the actual incidence of postoperative lateral sinus thrombosis following posterior fossa surgery might even be higher than reported here, because some clots might have resolved spontaneously between surgery and the first postoperative imaging.

\section{Risk Factors for Postoperative Lateral Sinus Thrombosis}

Oral contraception pill usage and medical history of venous thrombosis were significant risk factors for postoperative lateral sinus thrombosis in univariable analysis. These results are consistent with known risk factors for spontaneous cerebral vein or sinus thromboses, which also include female sex and oral contraception. ${ }^{8}$ Interestingly, a history of metastatic disease or meningioma, which are classic risk factors for deep venous thrombosis, were not found to be significant risk factors in the present study. ${ }^{5,10,15}$

Regarding surgical technique, exposing the midline and exposing the lateral sinus, even without damaging it, were significant risk factors for postoperative lateral sinus thrombosis, as previously suggested. ${ }^{12}$ However, we did not observe a higher risk of postoperative pseudotumor cerebri or hydrocephalus in patients with a postoperative lateral sinus thrombosis. ${ }^{12}$ The lateral sinus exposure may lead to its thrombosis through the desiccation of the dura surrounding the sinus or traction or suspension of the sinus itself, or of draining veins. Thus, good surgical practice should avoid unnecessary lateral sinus exposure and retraction. When the sinus has to be exposed or manipulated during surgery, it should be protected by regular dampening and the application of protective material such as damp cottonoids ${ }^{9}$ and by regular release of any retraction, if applied.

The intraoperative unintentional opening of the lateral sinus and the location of the lesion were not significant risk factors for postoperative lateral sinus thrombosis in our series. Although the lesion size has been previously identified as a risk factor for lateral sinus thrombosis following surgery for cerebellopontine angle tumors,,$^{13}$ we did not find such an association in our series. Other surgical mechanisms could be involved that could not be assessed retrospectively; for instance, the exact position of the head and neck that could lead to cervical vein compression, or the presence of a central venous jugular catheter that could induce extensive jugular vein thrombosis. Moreover, we may have failed to identify additional risk factors for postoperative lateral sinus thrombosis due to the limited size of our population.

\section{Consequences of Postoperative Lateral Sinus Thrombosis}

None of the 12 cases of postoperative lateral sinus thrombosis identified here were symptomatic. Generally, the most common symptom for spontaneous cerebral vein or sinus thrombosis is headaches, reported in $70 \%$ of cases, ${ }^{8}$ but during the postoperative period this symptom is both common and nonspecific. The good tolerance we observed is strikingly different when compared with spontaneous lateral sinus thrombosis. ${ }^{2}$ This may be explained by the existence of collateral veins, by a dominant contralateral lateral sinus, or by incomplete sinus occlusion allowing for some venous flow. Indeed, from a surgical point of view, it is agreed that unilateral sacrifice of a lateral sinus is well tolerated, ${ }^{11}$ although it can also lead to other more serious complications, such as pseudotumor cerebri or hydrocephalus. ${ }^{12}$ Moreover, postoperative sinus thrombosis is a local phenomenon secondary to surgery close to the sinus; thus, it probably cannot be compared with spontaneous cerebral venous thrombosis, which is a systemic problem.

However, postoperative lateral sinus thrombosis could lead to serious complications. Keiper et al. reported a $4.7 \%$ incidence of hydrocephalus secondary to a lateral sinus thrombosis after suboccipital or translabyrinthine craniectomy. ${ }^{12}$ Zuurbier et al. reported a $15.1 \%$ incidence of hydrocephalus secondary to a spontaneous cerebral sinus thrombosis. ${ }^{16}$ In the present study, hydrocephalus, requiring internal CSF diversion but not leading to permanent impairment, appeared in 2 of 12 patients (16.7\%) with a postoperative lateral sinus thrombosis. However, the exact origin of the hydrocephalus is a matter of debate during the early postoperative period because the underlying disease, surgical procedure, and location of the lesion may equally account for it.

\section{Anticoagulation Therapy}

The decision whether to treat an asymptomatic patient with postoperative lateral sinus thrombosis during the early postoperative period is a dilemma. There are no guidelines addressing how these patients should be managed. Despite modest available evidence, spontaneous cerebral sinus thromboses are treated with treatment-dose anticoagulant therapy, which appears to be safe and associated with a reduction in the risk of death or dependency. ${ }^{3,4}$ However, treatment-dose anticoagulant therapy during the immediate postoperative period carries a high risk of hemorrhage. The problem for the surgeon is how to balance the risks of the sinus thrombosis with the risks of causing iatrogenic hemorrhage with anticoagulation therapies.

The treatment-dose anticoagulant therapy seemed to increase the rate of long-term lateral sinus recanalization (85.7\% vs 20\%; not statistically significant, probably due to a lack of statistical power) but, on the other hand, it in- 
creased significantly the incidence of surgical complications $(56.2 \%$ vs $27 \%$; $p=0.020)$. Moore et al..$^{13}$ reported that 5 patients who were treated with immediate treatmentdose anticoagulant therapy (intravenous heparin, followed by Coumadin for 6 months) for lateral sinus thromboses after resection of a cerebellopontine tumor did not have any iatrogenic complications.

The present observational study does not allow suggestion of guidelines on whether to introduce treatmentdose anticoagulant therapy for postoperative lateral sinus thrombosis. This is because the practical management of each case was discussed on an individual basis, with the incorporation of medical history, intraoperative findings, extent of the lateral sinus thrombosis, timing of diagnosis, postoperative complications, and surgeon's preference. In our series, immediate postoperative treatment-dose anticoagulant therapy was not associated with a higher risk of intracranial hemorrhage complications, but 3 treated patients developed scar problems and 1 of them required repeated lumbar punctures and a second-look surgery.

\section{Conclusions}

Overall, postoperative lateral sinus thrombosis following posterior fossa surgery for a space-occupying lesion is asymptomatic and well tolerated in adults. Hence, there is still equipoise regarding the practical efficacy of treatment-dose anticoagulant therapy, which is limited to radiological lateral sinus recanalization and is associated with higher rates of postoperative complications. As a practical message, we propose that well-tolerated postoperative lateral sinus thrombosis following posterior fossa surgery in asymptomatic patients should be followed conservatively, without systematic introduction of a treatment-dose anticoagulant therapy, together with close clinical and radiological follow-up to identify early any thrombosis-linked complications. However, because the retrospective design of this observational study precludes the control of confounders that may have biased the introduction of treatment-dose anticoagulant therapy, no definite therapeutic guidelines can be drawn. A prospective trial should be considered and built in light of these preliminary epidemiological observations.

\section{Acknowledgments}

The following physicians are greatly acknowledged (in alphabetical order): Georges Abi-Lahoud, Felipe Andreiuolo, Laurent Arnaud, Francine Chassoux, Anaïs Chivet, Frédéric Dhermain, Sarah Dumont, Myriam Edjlali-Goujon, Sylvie Godon-Hardy, Maria Koziak, Elisabeth Landré, Emmanuelle Lechapt-Zalcmann, Guillaume Louvel, Michael Mann, Jean-Louis Mas, Eric Méary, Charles Mellerio, Catherine Miquel, Olivier Naggara, François Nataf, Denis Trystram, Baris Turak, and Pascale Varlet.

\section{References}

1. Browd SR, Ragel BT, Davis GE, Scott AM, Skalabrin EJ, Couldwell WT: Prophylaxis for deep venous thrombosis in neurosurgery: a review of the literature. Neurosurg Focus 17(4):E1, 2004

2. Coutinho JM: Cerebral venous thrombosis. J Thromb Haemost 13 (Suppl 1):S238-S244, 2015

3. Coutinho JM, de Bruijn SFTM, deVeber G, Stam J: Anticoagulation for cerebral venous sinus thrombosis. Stroke 43:e41-e42, 2012
4. Coutinho JM, Seelig R, Bousser MG, Canhão P, Ferro JM, Stam J: Treatment variations in cerebral venous thrombosis: an international survey. Cerebrovasc Dis 32:298-300, 2011

5. Eisenring CV, Neidert MC, Sabanés Bové D, Held L, Sarnthein J, Krayenbühl N: Reduction of thromboembolic events in meningioma surgery: a cohort study of 724 consecutive patients. PLoS One 8:e79170, 2013

6. Farb RI: The dural venous sinuses: normal intraluminal architecture defined on contrast-enhanced MR venography. Neuroradiology 49:727-732, 2007

7. Flinn WR, Sandager GP, Silva MB Jr, Benjamin ME, Cerullo LJ, Taylor M: Prospective surveillance for perioperative venous thrombosis. Experience in 2643 patients. Arch Surg 131:472-480, 1996

8. Geisbüsch C, Lichy C, Richter D, Herweh C, Hacke W, Nagel S: [Clinical course of cerebral sinus venous thrombosis. Data from a monocentric cohort study over 15 years.] Nervenarzt 85:211-220, 2014 (Ger)

9. Hervey-Jumper SL, Breshears J, Berger MS: Gelfoam scaffold for vein prolapse during brain tumor surgery. World Neurosurg 82:912.e11-912.e13, 2014

10. Hoefnagel D, Kwee LE, van Putten EHP, Kros JM, Dirven CMF, Dammers R: The incidence of postoperative thromboembolic complications following surgical resection of intracranial meningioma. A retrospective study of a large single center patient cohort. Clin Neurol Neurosurg 123:150-154, 2014

11. Kapp JP, Gielchinsky I, Deardourff SL: Operative techniques for management of lesions involving the dural venous sinuses. Surg Neurol 7:339-342, 1977

12. Keiper GL Jr, Sherman JD, Tomsick TA, Tew JM Jr: Dural sinus thrombosis and pseudotumor cerebri: unexpected complications of suboccipital craniotomy and translabyrinthine craniectomy. J Neurosurg 91:192-197, 1999

13. Moore J, Thomas P, Cousins V, Rosenfeld JV: Diagnosis and management of dural sinus thrombosis following resection of cerebellopontine angle tumors. J Neurol Surg B Skull Base 75:402-408, 2014

14. Nurmohamed MT: Thromboprophylaxis in neurosurgical patients. Semin Hematol 37 (3 Suppl 5):15-18, 2000

15. Watson HG, Keeling DM, Laffan M, Tait RC, Makris M: Guideline on aspects of cancer-related venous thrombosis. Br J Haematol 170:640-648, 2015

16. Zuurbier SM, van den Berg R, Troost D, Majoie CB, Stam J, Coutinho JM: Hydrocephalus in cerebral venous thrombosis. J Neurol 262:931-937, 2015

\section{Disclosures}

The authors report no conflict of interest concerning the materials or methods used in this study or the findings specified in this paper.

\section{Author Contributions}

Conception and design: Pallud, Oppenheim. Acquisition of data: Pallud, Apra, Kotbi. Analysis and interpretation of data: Pallud, Apra, Corns. Drafting the article: Pallud, Apra, Corns, Oppenheim. Critically revising the article: Pallud, Turc, Corns, Pagès, Souillard-Scémama, Dezamis, Parraga, Meder, Sauvageon, Devaux, Oppenheim. Reviewed submitted version of manuscript: Pallud. Approved the final version of the manuscript on behalf of all authors: Pallud. Statistical analysis: Pallud, Apra, Turc. Administrative/technical/material support: Pallud. Study supervision: Pallud.

\section{Correspondence}

Johan Pallud, Service de Neurochirurgie, Hôpital Sainte-Anne, 1, rue Cabanis, 75674 Paris Cedex 14, France. email: johanpallud@ hotmail.com. 